\title{
GIẢM TÍNH ĐA DẠNG Ở ĐỘNG, THỰC VẬT
}

\section{Thảm họa môi trường.}

- Đa dạng sinh học có vai trò là cơ sở cung cấp thực phẩm, là nền tảng cho sức khỏe loài người, giữ vị trí quan trọng trong dinh dưỡng của con người thông qua vai trò trong việc sản xuất thực phẩm toàn cầu; đảm bảo năng suất bền vững của đất và cung cấp nguồn gen cho cây trồng. ${ }^{1}$

- Thực trạng: Trong những thập kỷ qua, sự suy thoái đa dạng sinh học đã xảy ra với một tốc độ nhanh chóng trên thế giới, ở cả các nước phát triển như Mỹ, Nhật đến các nước chậm phát triển ở châu Phi, châu Á và Mỹ Latinh. Hiện nay có hơn 1 triệu loài động, thực vật trên khoảng tám triệu loài trên Trái Đất đứng trên bờ vực nguy hiểm. Ở Việt Nam, từ các dữ liệu phân tích, cho thấy $21 \%$ các loài thú, $6.5 \%$ các loài chim, $19 \%$ các loài bò sát, $24 \%$ các loài lượng cư, $38 \%$ các loài cá và $2.5 \%$ các loài thực vật có mạch bị đe doạ. ${ }^{2} 3$ - Các nguyên nhân chính là: Do thiên tai; sự ô nhiễm (hoá thạch: dầu, khí, than..)...Tốc độ gia tăng dân số, tốc độ khai thác thiên nhiên của con người, quá trình đô thị hóa, phát triển nông nghiệp để đáp ứng dân số tăng nhanh, giảm diện tích rừng và ô nhiễm môi trường. ${ }^{4} 56$

- Hậu quả, tác hại của việc giảm đa dạng động, thực vật: mất cân bằng sinh thái, ảnh hưởng trực tiếp đến môi trường sống của con người, đe dọa sự phát triển bền vững của trái đất. Ảnh hưởng đến an ninh lương thực, con người phải đối mặt với nguy cơ đói nghèo. ${ }^{7}$

- Vì vậy chúng ta cần nâng cao nhận thức, thay đổi hành vi của con người về bảo tồn đa dạng sinh học.

\section{Sự thất bại của các chính sách}

- "Thập niên Liên hợp quốc về đa dạng sinh học" giai đoạn 2011-2020 chưa đạt được tham vọng đã đề ra về đa dạng sinh học trong khuôn khổ chương trình nghị sự phát triển bền vững 2030 và không bảo vệ được hệ sinh thái vốn đóng vai trò sống còn đối với con người. ${ }^{8}$

\footnotetext{
1 “ECOLOGYThe Importance of Biodiversity," Panorama, n.d., https://www.revistapanorama.com/en/the-importance-ofbiodiversity/.

${ }^{2}$ V. M. Stevens \& S. Blanchet H. De Kort, J. G. Prunier, S. Ducatez, O. Honnay, M. Baguette, "Life History, Climate and Biogeography Interactively Affect Worldwide Genetic Diversity of Plant and Animal Populations," Nature Communications, 2021, https://www.nature.com/articles/s41467-021-20958-2.

${ }^{3}$ Wilfried Thuiller \& Cyrille Violle Nicolas Loiseau, Nicolas Mouquet, Nicolas Casajus, Matthias Grenié, Maya Guéguen, Brian Maitner, David Mouillot, Annette Ostling, Julien Renaud, Caroline Tucker, Laure Velez, "Global Distribution and Conservation Status of Ecologically Rare Mammal and Bird Species," Nature Communications, 2020, https://www.nature.com/articles/s41467-020-18779W.

${ }^{4}$ GUOHUAN SU HTTPS://ORCID.ORG/0000-0003-0091-9773 MAXIME LOGEZ HTTPS://ORCID.0RG/0000-0001-9843-0495JUN XUSHENGLI TAO HTTPS://ORCID.ORG/0000-0002-2145-4736SÉBASTIEN VILLÉGER HTTPS://ORCID.0RG/0000-0002-2362-7178AND SÉBASTIEN BROSSE, "Human Impacts on Global Freshwater Fish Biodiversity," Science, 2021, https://www.science.org/doi/10.1126/science.abd3369.

${ }^{5}$ Forest Isbell (lowa State University), "Causes and Consequences of Biodiversity Declines," The Nature Education, n.d., https://www.nature.com/scitable/knowledge/library/causes-and-consequences-of-biodiversity-declines-16132475/.

${ }^{6}$ Richard Rastall Trịnh Thăng Long, Hoàng Việt Anh, Nguyễn Xuân Đặng, "Giám Sát Đa Dạng Sinh Học," SNV, 2016, https://snv.org/cms/sites/default/files/explore/download/prmvn.pdf?fbclid=IwAR3axKYxZe8fG5TR06JDLcd6Egcq3W0JFLM8f9iHF69hi6N_ncThZGX2TEY.

${ }^{7}$ David G. Reid \& Axel G. Rossberg Tak Fung, Keith D. Farnsworth, "Impact of Biodiversity Loss on Production in Complex Marine Food Webs Mitigated by Prey-Release," Nature Communications, 2015, https://www.nature.com/articles/ncomms7657.

8 Thanh Hương (TTXVN/Vietnam+), “COP 15 Ra Tuyên Bố Kêu Gọi Hành Động Khẩn Cấp Bảo Tồn Đa Dạng Sinh Học,” VietNam+, 2021, https://www.vietnamplus.vn/cop-15-ra-tuyen-bo-keu-goi-hanh-dong-khan-cap-bao-ton-da-dang-sinh-hoc/747029.vnp.
} 
- Năm 2010, 196 quốc gia thuộc công ước đa dạng sinh học của Liên Hợp Quốc đã đồng ý với 20 mục tiêu bảo tồn thực vật gọi là mục tiêu đa dạng sinh học AICHI . Tuy nhiên chỉ có $6 / 20$ mục tiêu đạt được 1 phần kết quả và 1 số chỉ tiêu thậm chí đang đi sai chiều. 910

\section{Tuy nhiên thế giới vẫn tiếp tục nỗ lực}

- Trong thế kỉ qua, thế giới đã hiện thực hóa nỗ lực bằng cách thành lập các tổ chức phi lợi nhuận, mở nhiều cuộc hội nghị, kí kết công ước bảo tồn động thực vật: Tổ chức bảo tồn Động thực vật thế giới Fauna \& Flora International ${ }^{11}$, Tổ chức động vật châu Á ( Animals Asia Foundation) ${ }^{12}$, Tổ chức bảo vệ động vật quốc tế Animal Defenders International (ADI) ${ }^{13}$, Hiệp hội bảo tồn Động vật hoang dã ( WCS) ${ }^{14}$, Ngày quốc tế Đa dạng sinh học vào ngày 22 tháng 5 hàng năm ${ }^{15}$, Công ước CITES ${ }^{16}, \ldots$

- Ngày 11-15/10/2021, Hội nghị lần thứ 15 các bên tham gia Công ước về đa dạng sinh học hay COP15 kêu gọi thế giới đồng thuận ngăn chặn khủng hoảng; hành động "khẩn cấp và phối hợp"của tất cả các bên, cam kết đảm bảo xây dựng, thực hiện có hiệu quả “Khung đa dạng sinh học toàn cầu sau năm 2020" nhằm đảo ngược tình trạng mất đa dạng sinh học hiện nay. Với tư cách là nước chủ nhà, Trung Quốc đã phát động quỹ bảo vệ sinh học cho các quốc gia đang phát triển và công bố khoản đóng góp 1,5 tỷ nhân dân tệ cho quỹ này. ${ }^{17}$

\section{Kết luận}

Tóm lại, suy giảm đa dạng sinh học là sự suy giảm chất lượng và số lượng của các loài sinh vật, gây ảnh hưởng xấu cho đời sống của con người và thiên nhiên.

Trước áp lực của sự phát triển và tác động của môi trường trên toàn cầu, nguy cơ suy giảm, suy thoái đa dạng động- thực vật đã gây ra những hệ quả nghiêm trọng đối với sự phát triển bền vững của đất nước. Trong bối cảnh hiện nay, việc tăng cường bảo tồn sự đa dạng động- thực vật là vấn đề cấp bách của các quốc gia. Thế giới cần hành động mạnh mẽ, giải pháp kịp thời, nỗ lực triệt để trong công tác bảo vệ và quản lí tốt hệ sinh thái.

\footnotetext{
9 “Bảo vệ Đa Dạng Sinh Học: Sự Thất Bại Của Các Quốc Gia,” Tia Sáng, 2020, https://tiasang.com.vn/-doi-moi-sang-tao/Bao-ve-dadang-sinh-hoc-Su-that-bai-cua-cac-quoc-gia--25525.

10 “Ipbes_global_assessment_report_summary_for_policymakers_vi,” n.d., https://ipbes.net/sites/default/files/202104/ipbes_global_assessment_report_summary_for_policymakers_vi.pdf.pdf?fbclid=IwAR2oY08TKUXE27bpQpF0PDXV1FaQcfxpUrj7 WeHENGLyfE_5peS_6t5mlel.

11 "FAUNA AND FLORA INTERNATIONAL," n.d., https://www.fauna-flora.org/publications/.

12 "Animals Asia Foundation," Charity Clarity, n.d., https://www.charityclarity.org.uk/charities/animals-asia-foundation/.

13 “Animal Defenders International (ADI)," n.d., https://www.ad-international.org/adi_home/.

14 “Hiệp Hội Bảo Tồn Động Vật Hoang Dã ( WCS)," n.d., https://vietnam.wcs.org/VN.aspx.

15 “Ngày Quốc Tế Đa Dạng Sinh Học - 22/5/2020: 'Các Giải Pháp Của Chúng Ta Sẵn Có ở Thiên Nhiên,'” Vietnam Biodiversity, 2020, https://vietnamabs.gov.vn/huong-ung-ngay-quoc-te-da-dang-sinh-hoc-nam-2020/.

16 “CÔNG ƯớC QUỐC TẾ Về BUÔN BÁN CÁC LOẠI ĐộNG, THỰC VẬT HOANG DÃ NGUY CẤP (CITES)," Thư Viện Pháp Luật, n.d., https://thuvienphapluat.vn/van-ban/Tai-nguyen-Moi-truong/Cong-uoc-quoc-te-buon-ban-cac-loai-dong-thuc-vat-hoang-da-nguycap-CITES-107575.aspx.

17 “UN System Statement of Purpose: COP15," CEB, 2021, https://unsceb.org/un-system-statement-purpose-cop15.
} 
